\title{
Assessing individuals' re-gifting motivations
}

\section{Gianluigi Guido}

Department of Management, Economics, Mathematics, and Statistics University of Salento

Ecotekne Campus, Via per Monteroni, 73100 Lecce, Italy

gianluigi.guido@unisalento.it

\section{Giovanni Pino}

Department of Management, Economics, Mathematics, and Statistics University of Salento

Ecotekne Campus, Via per Monteroni, 73100 Lecce, Italy giovanni.pino@unisalento.it

\author{
Alessandro M. Peluso \\ Department of Management, Economics, Mathematics, and Statistics \\ University of Salento \\ Ecotekne Campus, Via per Monteroni, 73100 Lecce, Italy \\ alessandro.peluso@unisalento.it
}




\title{
Assessing individuals' re-gifting motivations
}

\begin{abstract}
This research investigates individuals' motivations to pass gifts on to other people, a practice known as re-gifting. In three studies, we develop and test a tridimensional scale of re-gifting motivations that encompasses: an individualistic motivation, whereby the re-gifter tries to maximize his/her personal utility; a detachment motivation, whereby the re-gifter seeks to preserve his or her relational distance from the re-giftee and/or the first giver; and a virtuous motivation, which captures the re-gifter's morally and socially desirable intent to benefit the re-giftee and/or preserve the material value of the gift. The individualistic and detachment motivations are stronger when the re-giftee is a distant other, whereas the virtuous motivation is stronger when the re-giftee is a close other. These results shed light on the social function of re-gifting and suggest that, despite often being stigmatized as a censurable behavior, this practice can sometimes be driven by a morally acceptable motivation.
\end{abstract}

Keywords: Re-gifting measurement, re-gifting motivations, relational closeness, second-hand gifts. 


\section{Assessing individuals' re-gifting motivations}

\section{Introduction}

Re-gifting is a "form of gift giving where the gift is second-hand and that fact may or may not be concealed from the recipient" (Swilley, Cowart, \& Flynn, 2014, p. 259). This practice is common in today's society: in the U.S., more than thirty percent of people engage in regifting during the holiday season (American Express, 2013). In doing so, people who pass their gifts on (i.e., re-gifters) to other people (i.e., re-giftees) may contribute to reducing a considerable waste of economic value. In 2013, for instance, the average American spent over $\$ 700$ on Christmas gifts (Gallup, 2013). However, estimates indicate that up to one third of gift spending is wasted because many gifts do not match the recipients' preferences and are thus unused or discarded (Waldfogel, 1993).

Re-gifting gives unwanted gifts a second chance of being used and, as such, could help people reduce waste and consume fewer material resources for new gifts. In accordance with this view, several voluntary initiatives, such as the National Re-gifting Day in the U.S. and Le Grand Don in Europe, have been undertaken in order to promote re-gifting as a desirable behavior. Re-gifting has also been encouraged by major media (e.g., ABC News, 2014; CBS, 2015), which try to inform consumers about its etiquette (Ertimur, Muñoz, \& Hutton, 2015; Swilley et al., 2014), as well as by mobile technology experts, who have developed new applications aimed at facilitating re-gifting (Adweek, 2012).

However, companies may consider this behavior economically unsustainable, insofar as it reduces new gift sales, and thus oppose it — for example, by adding options to customize their products and make them less suitable for re-gifting (Ertimur et al., 2015). Moreover, while consumers might look at re-gifting as an economically and environmentally sustainable practice (Green America, 2016; Mansvelt \& Robbins, 2011), they may also think that second- 
hand gifts are undesirable items and therefore consider re-gifting an offensive behavior (Adams, Flynn, \& Norton, 2012). Indeed, although re-gifting may occur in an overt way by informing re-giftees about the second-hand nature of the re-gifts, re-gifters might engage in a covert behavior by pretending that the re-gifts are new. Covert re-gifting is generally considered deceitful and disrespectful to the re-giftee (Swilley et al., 2014), as well as to the first giver, that is, the person who bought the gift and gave it first. Indeed, a gift is generally regarded as inalienable because it represents a part of the first giver's self (Mauss, 1925). For these reasons, re-gifting continues to be stigmatized as a socially censurable behavior in the majority of Western societies.

Given this complex situation, understanding the motivations behind individuals' decisions to engage in re-gifting may help to clarify its role in social relationships. The few studies published on this topic have explored such motivations, but only via qualitative techniques. For instance, Ertimur et al. (2015) proposed four different re-gifting modes associated with different re-gifters' goals: a pragmatic mode, whereby the re-gifter passes on a gift in order to accomplish a gift-giving obligation in a timely and efficient way; a retaliatory mode, whereby the re-gifter seeks to affirm his/her selfhood and teach social norms to the re-giftee; an altruistic mode, whereby the re-gifter aims to please the re-giftee and express care for him/her; and a playful mode, whereby the re-gifter engages in this behavior for fun. However, research on re-gifting motivations is still in its infancy. In particular, very little effort has been made to empirically assess whether and how such motivations change on the basis of the relational closeness between re-gifters and re-giftees.

The present work contributes to this area of inquiry by developing a measurement scale that quantitatively assesses re-gifting motivations in order to better explain why people engage in re-gifting. This work adopts a mixed research approach that combines both qualitative and quantitative techniques across three different studies. Study 1 determines an 
initial set of motivations by qualitatively exploring why consumers engage in re-gifting. Study 2 develops and validates a scale based on Study 1's results. Study 3 provides an experimental test of the scale's predictive validity, using real re-gifting situations to show that the assessed motivations vary in intensity according to whether the re-giftee is a close or distant other. Through such findings, the present research proposes a new and comprehensive interpretative framework of re-gifting motivations that could pave the way for further investigations.

The remainder of the paper is organized as follows: The next section briefly reviews the previous literature on re-gifting. The following sections present the three empirical studies and then discuss their results and implications. The final section details the limitations of this research alongside directions for future studies.

\section{Conceptualizing the re-gifting behavior}

Previous literature defined re-gifting as a practice through which the re-gifter disposes of his or her gifts by passing them on to other people (Sherry, 1983; see also Cruz-Cárdenas, González, \& del Val Núñez, 2015). Several tactics can be employed to enact re-gifting (Ertimur et al., 2015), such as “decontaminating" the gift (i.e., removing tags and greeting cards) in order to make it appear as a new item; personalizing the gift (e.g., by adding a name); or dividing it in multiple parts or transforming it in order to disguise its second-hand nature. However, people might also pass unwanted gifts on to others exactly as they were originally received from the first giver.

It is commonly believed that items being re-gifted represent careless gifts that people pass on to others to whom they are not particularly tied and that do not create any obligation to reciprocate (Ormandy, 2011; Swilley et al., 2014). However, in particular situations, re-gifts have a strong symbolic meaning. This may happen when such items are particularly desired 
by the re-giftee or when they represent family heirlooms that are handed down from one generation to another (Curasi, Price, \& Arnould, 2004; Ertimur et al., 2015; Author, 2014; Swilley et al., 2014). Intergenerational re-gifts are normally considered highly sentimental, inalienable and "pure" gifts (Malinowski, 1978) because they cannot be given to people other than family members.

The variety of situations in which re-gifting may occur can elicit positive emotions (e.g., amusement and fun) or negative emotions (e.g., regret and guilt) in re-gifters and re-giftees. Specifically, gifts that are highly desired by or meaningful to re-giftees (such as family heirlooms) normally arouse positive emotions in both re-gifters and re-giftees. Such gifts are passed on overtly and solidify familial ties (Ertimur et al., 2015). Similarly, gifts that are passed on purely for fun, such as during the re-gifting parties that are quite popular in the U.S. (e.g., the white elephant exchange or Secret Santa), also arouse positive emotions. In such special occasions, re-giftees are aware that the gifts are repurposed items, and the principal aim of re-gifting is to build or strengthen a sense of community among people partaking in these events. At the same time, re-gifters and re-giftees may experience negative emotions (e.g., fear, shame), especially when re-gifting occurs covertly (Swilley et al., 2014). Re-gifters may resort to this deceitful form of re-gifting for pragmatic reasons, although it could undermine their social relationship with re-giftees. Re-giftees might indeed realize the second-hand nature of the re-gift(s) and thus judge this gesture as a disrespectful act (Ruth, Otnes, \& Brunell, 1999). Re-gifters, realizing the opportunity to use re-gifts for retaliatory purposes, might even reveal the gift's second-hand nature to re-giftees in a deliberate attempt to teach them a lesson (Ertimur et al., 2015). 


\subsection{Re-gifting motivations}

Because re-gifting can be construed as a particular type of gift-giving (Swilley et al., 2014), some of the motivations associated with gift-giving may also apply. Such motivations might be broadly classified as: altruistic (i.e., other-focused) motivations; and egoistic (i.e., self-focused) motivations (Belk \& Coon, 1993; Otnes \& Beltramini, 1996; Paolacci, Straeter, \& de Hooge, 2015; Sherry, 1983). Altruistic motivations lead people to give gifts to genuinely please the recipients, express esteem and/or love for them, and ultimately increase their happiness and well-being without expecting any reward in return (Belk \& Coon, 1993; Malinowski, 1978). In contrast, egoistic motivations lead people to give gifts to ingratiate themselves with the recipients (Ruth et al., 1999; Waterman, 1981), obligate them to reciprocate with gifts of at least the same value (Gouldner, 1960; Mauss, 1925), enhance their own social position (Segev, Shoham, \& Ruvio, 2012; Sherry, 1983), or simply establish new social bonds (Belk \& Coon, 1993; Caplow, 1982; Cheal, 1988; Lowrey, Otnes, \& Ruth, 2004).

The relative strength of altruistic versus egoistic motivations depends on the nature of the relationship between gift-givers and recipients (Ruth et al., 1999). Altruistic motivations are stronger when recipients are emotionally close to gift-givers (Joy, 2001). In support of this notion, past research has shown that individuals exchange gifts more frequently when they are in close rather than distant relationships (Belk, 1979) and the gifts exchanged within close relationships are more expensive than those exchanged within distant relationships (Caplow, 1982; Saad \& Gill, 2003). In contrast, when recipients are emotionally distant from giftgivers, gift-giving tends to be driven by egoistic motivations and aimed at increasing the giftgivers' utility (Joy, 2001).

These principles can be extended to re-gifting. Exploratory research indeed suggests that re-gifters may engage in this behavior for either altruistic or egoistic motivations. Re-gifters 
are driven by altruistic motivations when they pass on unwanted gifts in order to express their care for re-giftees, especially when they are friends or loved ones who desire the re-gifters' gifts (Ertimur et al., 2015; Swilley et al., 2014). On the opposite end, re-gifters are moved by egoistic motivations when they pass on unwanted gifts for the following reasons: to quickly alleviate the problems connected with gift-giving (e.g., devoting time and money to the selection and purchase of gifts, being unaware of the recipient's tastes and desires, dealing with an unexpected invitation, etc.; known as pragmatic re-gifting); to affirm their selfhood and/or avenge an offense by the re-giftee (retaliatory re-gifting), or just to amuse themselves by participating in the playful exchange of second-hand gifts (playful re-gifting). Previous studies (Homick, 2007; Ormandy, 2011; Swilley et al., 2014) suggest that re-gifting is a generally acceptable behavior when the relationship between two individuals is distant, but could be considered disrespectful when it occurs among closely tied individuals.

Despite the relevance of such qualitative findings, no study to date has quantitatively assessed how re-gifting motivations relate to the type of relationship between re-gifters and re-giftees. The present research aims to fill this gap by developing a multidimensional scale of re-gifting motivations. To this end, we embraced a consolidated approach (Churchill, 1979; Gerbing \& Anderson, 1988; see also Blankson, 2008; Malcarne et al., 2006; Russell, Norman, \& Heckler, 2004; Van Dun, Bloemer, \& Henseler, 2011), which entails using a qualitative inquiry to develop an initial set of items for a measurement scale; quantitatively implementing the scale to assess its dimensional structure; and then validating the detected structure. Thus, we performed an exploratory study (Study 1) with two focus groups to devise the items for our scale, followed by a survey study (Study 2) to test the scale's dimensionality. Then, to obtain evidence of the scale's external validity, we employed another survey study (Study 3) that assessed whether the relational closeness between re-gifters and re-giftees moderates the strength of re-gifting motivations. 


\section{Study 1: Qualitative investigation into the re-gifting motivations}

In contrast to previous studies, which have investigated re-gifting in a North American cultural context, the present research focused on Italian consumers. Re-gifting is quite popular in Italy and the number of Italian consumers who pass their gifts on to other people increases year after year (Coldiretti, 2014, 2015). Because of this focus on Italian consumers, we first needed to develop an initial set of items that fully reflect what Italian consumers think about re-gifting. To this end, we employed the focus group technique (Carson, Gilmore, Perry, \& Gronhaug, 2001; Stewart, Shamdasani, \& Rook, 2006), which past studies have used to explore re-gifting motivations (Swilley et al., 2014). Focus groups stimulate the comparison of participants' different points of view (Carrigan \& Attalla, 2001), thus allowing a richer and deeper understanding of the social dimension of the examined construct. We conducted two focus groups using the same procedure. Our aim with the first focus group was to delineate a preliminary set of motivations, whereas the second one served a confirmatory purpose, assessing whether the initial data was sufficiently encompassing. Each focus group occurred in a different medium-sized Italian city and was attended by 16 participants.

\subsection{Procedure}

Participants in the first focus group (mean age $=33, S D=7.10,50 \%$ females) were recruited through a snowball sampling procedure and had different occupations (see Table 1 for details). A professional moderator stimulated group interaction and discussion during the meeting. The moderator introduced the topic by describing re-gifting as a behavior that, despite sometimes being taboo for many people, is so popular that anyone, at least once, has passed a gift on to another person. This brief introduction served to encourage participants to talk as openly as possible about re-gifting. The moderator provided participants with a blank paper and asked them to recall whether they had ever engaged in re-gifting, the object that 
they re-gifted, and the recipient of their re-gift. Participants who acknowledged that they had passed on gifts were asked to write a short description of at least one situation in which they engaged in re-gifting and why they did so. Seven participants stated that they never engaged in re-gifting. Therefore, they were instructed to report why they thought people in general engage in re-gifting by writing a short description of the motivations behind this behavior. Afterward, the moderator invited all participants to discuss their notes in order to understand what may drive people to engage in re-gifting. The discussion lasted about 90 minutes.

This same focus group procedure was employed two weeks later with a different sample of 16 Italian consumers (mean age $=35, S D=7.90,50 \%$ females). For the second focus group, six participants stated that they never engaged in re-gifting and the discussion lasted about one hour.

Table 1 about here

\subsection{Results}

The group discussions were audio recorded, transcribed verbatim, and coded without the aid of software tools by two trained research assistants who followed the established inductive coding procedure (Mayring, 2000; see also Kassarjan, 1977; Spiggle, 1994). Following this procedure, they repeatedly read all data: namely, the audio file transcripts from both recordings along with participants' pre-discussion notes. Then, they sought to identify key concepts and set out a list of propositions, each capturing a re-gifting motivation, from participants' responses. The coders then compared their lists and discussed all the propositions in order to clarify the ambiguous ones or merge those that captured the same motivation, thereby creating an initial coding scheme of eighteen propositions. Each coder independently tested this scheme on one half of the data and then compared their results in 
order to reconcile divergent interpretations through discussion. After eliminating two redundant propositions and slightly revising the remaining ones, they independently applied a finalized coding scheme of sixteen propositions to all data (see Table 2) and reached complete agreement on $91 \%$ of the codified re-gifting motivations.

In a subsequent step, the coders grouped the propositions based on their conceptual similarity and identified three main categories of re-gifting motivations (see also Table 2) that reflect and conceptually expand those detected by previous research (i.e., Ertimur et al., 2015). The first category reflected individuals' willingness to engage in re-gifting to maximize their personal utility. The second category reflected individuals' willingness to engage in re-gifting to maintain or increase the relational distance from the re-giftee and/or the first giver. The third category reflected individuals' willingness to engage in re-gifting to act in a morally desirable way, by benefitting others and/or minimizing the waste of unwanted gifts. Hence, these motivations were respectively labelled as individualistic, detachment, and virtuous

Table 2 about here

\subsubsection{Individualistic motivations}

The content analysis revealed that re-gifting can be enacted for practical reasons. Regifters might choose to engage in this behavior because they might not have enough money and/or time to devote to the purchase of a new gift or might wish to avoid the psychological effort required by a new gift purchase. These utilitarian motivations have also been detected in the gift-giving literature (Otnes, Lowrey, \& Kim, 1993) and, as noted in prior studies (Ertimur et al., 2015), reflect a "pragmatic" side of re-gifting (see also Homick, 2007):

Participant 16: "I passed on a gift four years ago. It was Christmas time. I had to buy a gift for a colleague of mine, but I didn't want to go out and look for it. At 
Christmas, shops are crowded and it takes such a long time to purchase something. I didn't have much money either. So, I decided to pass on to him a wallet that I had received for my eighteenth birthday."

Participant 21: "A few months ago, I re-gifted a post-shave balm to my roommate. He invited me to his birthday party, but I was too tired to go out and purchase a gift for him."

The re-gifter might be further incentivized to re-gift if his or her gift is already wrapped.

Recipients normally expect to receive wrapped gifts during gift exchanges, so these gifts are suitable to be passed on (Caplow, 1984). Furthermore, participants were more likely to re-gift when they felt uncertainty about choosing the right gift for the recipient (Ertimur et al., 2015; Otnes et al., 1993):

Participant 14: “A few years ago, I arranged a party for Mother's Day. I received three potted plants: the first was given to me by my brother, the second by my friend Mary, and the third by my daughter Sonia. At the end of the party, the one Sonia gave to me remained wrapped. I decided to take it to my mother-in-law."

Participant 17: "Someone introduced me a new fellow student at the beginning of this semester. Two months later, this guy invited me to his graduation party. I really did not know what to buy for him as we had been out together just a couple of times. Eventually, I decided to give him a belt that my parents had given me for my $24^{\text {th }}$ birthday. It was new. I wrapped it in a gift box and gave it to the guy."

However, re-gifters might pass on their gifts simply because they feel entitled to freely dispose of these items and are unconcerned with the consequences of this gesture. From this perspective, re-gifting may be seen as a peculiar type of giver-centered gift-giving that serves as an expression of personal freedom (Ruth et al., 1999):

Participant 15: "Many people pass on gifts when they feel free to do whatever they want with their belongings. You know, it may happen that one feels free to dispose of his/her gifts in the same way he/she disposes of money, clothes, or other stuff."

Participant 16: "I know a lot of people who are used to passing on their gifts. They do it because they do not care about the consequences of this choice. They simply do not care about what the recipient might think about them." 
Collectively, these motivations clearly denote re-gifters' individualistic orientation, reflecting their focus on both pragmatism (Ertimur et al., 2015) and personal utility.

\subsubsection{Detachment motivations}

People might engage in re-gifting to reciprocate another person's use of the same behavior. As noted by Ertimur et al. (2015), in such a case, re-gifting becomes a sort of vengeful behavior aimed at expressing the sense of hostility that re-gifters feel for re-giftees:

Participant 20: "It may happen that you engage in re-gifting when you receive a second-hand gift from a certain person. It is not so difficult to understand if someone is re-gifting you. So, when you have the opportunity, you'll do the same with that person."

Likewise, re-gifting might serve to express the re-gifters' weak affective commitment—or even unfriendliness (Schwartz, 1967) and distaste (Ruth et al., 1999)_for re-giftees or first givers. This finding is consistent with gift-giving studies suggesting that gifts may symbolize group membership and relational intimacy (and hence social integration) or, on the opposite end, affective distance (Sherry, 1983).

Participant 10: "[...] much depends on the person who gives you the gift. If this person annoys you, it's normal that you may want to rid yourself from his/her gifts. Or you may want to give him/her a second-hand gift. In this way you will tell that person how much you care for him/her."

Participant 11: “[...] People pass on gifts when they do not care about the recipients. A second-hand gift is not meant for the person to whom you give it. It's a 'quick' gift: you give it because you do not care about that person."

Following this line of reasoning, we also found that people may pass on the gifts of others for whom they no longer feel affection, such as ex-partners, in order to rid themselves of objects that have lost their initial affective meaning: 
Participant 12: "I have passed on many of the gifts that my ex-boyfriend gave me for Christmas and on other occasions. I did not want to see those things any more as they reminded me of him."

Moreover, people might engage in re-gifting to satisfy a sense of obligation imposed by social conventions (Swilley et al., 2014; see also Marcoux, 2009). Re-gifters may adopt this attitude when they pass unwanted gifts on to acquaintances, colleagues, distant relatives, and any other person to whom they do not feel closely tied. In doing so, they avoid generating a sense of indebtedness in re-giftees and maintain a certain relational distance:

Participant 8: "Once a colleague of my wife Lisa invited us to a barbecue at his country house. I did not know this person and felt a bit uncomfortable going there without bringing something. So, I suggested bringing him a box of chocolates that our neighbor had given us a couple of days before and that was still closed. We did this just to fulfil the sense of obligation that I felt in that moment."

Hence, these findings enrich previous research by suggesting that, beyond a purely vindictive and antagonistic aim (cf. Ertimur et al., 2014), re-gifting might be enacted to maintain or increase the relational distance between re-gifters and re-giftees, as well as between re-gifters and first givers, thus reflecting a broader detachment intent.

\subsubsection{Virtuous motivations}

In line with previous research (Ertimur et al., 2015; Swilley et al., 2014), we found that people are motivated to pass on unwanted gifts when they are confident that such gifts are desired and will be appreciated by re-giftees. In other cases, these objects are considered too valuable to keep for oneself, as they belonged to one's ancestors and hence are handed down through generations. As noted by prior studies (Ertimur et al., 2015; Swilley et al., 2014), such situations imbue second-hand gifts with a strong symbolic meaning and serve to enhance the relationship between the re-gifter, the re-giftee, and the first giver (cf. Belk \& Coon, 1993; Curasi et al., 2004): 
Participant 18: "A couple of years ago I gave a blue sweater that I have never worn to my brother-in-law. I was sure he would appreciate it because blue is his favourite color. The style of the jumper was very simple and similar to those he is used to wear. Fortunately, also the size was the right one."

Participant 26: "Last year my niece Marika invited me to her $18^{\text {th }}$ birthday party. I decided to give her the earrings that my uncle had given me for my $25^{\text {th }}$ birthday. I kept them for so many years and wore them only on two or three occasions. I'm sure I made the right choice. In that moment I only thought that the most important thing was to make Marika happy."

However, people might also feel motivated to engage in re-gifting when they have duplicate gifts or when they want to consciously avoid throwing unwanted gifts away. In doing so, they may wish to share their wealth with other persons and/or preserve the utility and economic value of their gifts. Such motivations denote re-gifters' clear intent to behave in a morally sound and environmentally friendly manner:

Participant 27: "I received three silver trays for my wedding and honestly I did not know what to do with all of them. I recycled the third one as a gift for an acquaintance's wedding. Why keep them all for me? It is a shame to spend money to purchase new gifts while keeping at home so many things that could be used by other persons."

Participant 22: "Throwing gifts away is more distasteful than passing them on to others. All gifts have a value and utility. Even those that one does not like. I have barely thrown away my gifts. It's a pity. Instead I have passed them on to other people."

In line with Ertimur et al. (2014), these results confirm that re-gifting might be triggered by altruistic intents and, at the same time, might be inspired by a deeper desire to act in an ethically correct way. Based on this finding, re-gifting can be considered a virtuous behavior.

\section{Study 2: Quantitative assessment of the re-gifting motivations}

Building on Study 1's qualitative findings, Study 2 develops and tests a measurement scale that quantitatively assesses re-gifting motivations. Sixteen different items were derived from the re-gifting motivations that emerged in Study 1 (e.g., "If I had two identical gifts, I would 
pass on one of them", "If I needed to save time, I would pass on one of my gifts"; 1 = Strongly disagree, 7 = Strongly agree). Two researchers, who were blind to the study's aim, checked these sixteen items for readability and clarity, providing suggestions on how to better capture the various motivations to engage in re-gifting. After revising some items based on these suggestions, we included the whole list of items in a closed-ended questionnaire.

To better understand the social domain of re-gifting, we included an additional set of eleven questions that were designed to reveal the types of persons who are more likely to receive second-hand gifts (e.g., "I would pass one of my gifts on to a colleague of mine", $1=$ Very unlikely, 7 = Very likely). Some of these persons are those to whom one is typically tied by a loose relationship (e.g., acquaintances and colleagues), whereas others are persons to whom one is closely tied (e.g., partners, close friends, parents, and siblings) (Caplow, 1982; Joy, 2001; Ruth et al., 1999, Saad \& Gill, 2003). Finally, the questionnaire gathered respondents' gender and age.

\subsection{Procedure}

We administered an online questionnaire to a sample of 300 respondents recruited from a national pool of Italian consumers. Of these, 171 individuals (mean age $=29.6, S D=11.18$, $74 \%$ female) accepted a formal invitation to take part in the survey and completed the questionnaire.

\subsection{Results}

\subsubsection{Exploratory analyses}

Table 3 reports the mean scores of the items regarding the types of persons who are more likely to receive second-hand gifts. Such scores indicate that people are more inclined to engage in re-gifting when re-giftees are distant others (i.e., acquaintances, colleagues, and 
employers) rather than close others (i.e., siblings, parents, grandparents, and partner). To support this argument, we performed a principal component analysis (with Varimax rotation) on the items regarding the types of persons who are likely to be re-giftees. The analysis yielded a two-factor solution. Specifically, five items associated with types of persons typically regarded as close others (i.e., siblings, parents, grandparents, partners, close friends) mainly loaded on the first factor with loadings higher than 0.80 , and loadings lower than 0.40 on the second factor. Three items associated with types of persons that could be typically qualified as distant others (i.e., colleagues, acquaintances, and employers) mainly loaded on the second factor with loadings higher than 0.80 , and loadings lower than 0.40 on the first factor. Three items regarding types of persons who can be both distant and close others (i.e., partners' parents, friends and relatives in general) loaded on both factors, with loadings higher than 0.40 , and were dropped. Therefore, the factor analysis was re-run on the remaining eight items obtaining the factor loadings reported in Table 3. Based on these findings, we combined the items that respectively loaded on the two distinct factors to obtain two indexes that reflected the likelihood to engage in re-gifting when re-giftees are either close or distant others. A paired sample t-test confirmed that respondents are more inclined to engage in regifting when the potential re-giftees are distant others $(M=3.60, S D=1.91)$ rather than close others $(M=2.13, S D=1.75, t(170)=-8.57 ; p<.001$, Cohen's $d=0.66)$. This finding reaffirms that individuals tend to pass their gifts on to relatively distant persons to whom they are loosely tied (Homick, 2007; Ormandy, 2011; Swilley et al., 2014).

Table 3 about here 


\subsubsection{Dimensions of the re-gifting motivation scale}

We ran an exploratory factor analysis (maximum likelihood method and Oblimin rotation) on the collected data, aiming to explore the dimensional structure of the initial set of items denoting re-gifting motivations and eliminate inconsistent items. The analysis yielded a threefactor solution capable of explaining $50 \%$ of the variance. However, three items were dropped from the analysis, namely: "If someone gave me something he/she already has, I think I would do the same with him/her", which exhibited a factor loading lower than 0.40 , and the items "If I had a gift that I did not unwrap, I would use it again as a gift" and "I would pass on a gift if I had to give it just to accomplish a social obligation", as they exhibited crossloadings close to 0.30 (Hair, Anderson, Tatham, \& Black, 1998).

Another exploratory factor analysis, conducted on the refined set of items, returned a threefactor solution that explained $62 \%$ of the variance. Each item mainly loaded one of the three dimensions, with factor loadings equal to or greater than 0.40 . Only one item (i.e., "If I received a highly valuable gift, I would give it to someone that is very important to me") exhibited a factor loading slightly lower than 0.40 . However, we decided to retain this item in the scale because it captured a peculiar facet of re-gifting that emerged in previous literature (Swilley et al., 2014), and because the relatively low factor loading associated with this item was counterbalanced by loadings on the other two factors that were very close to zero.

Each of the three dimensions exhibited an adequate level of internal consistency as assessed by Chronbach's $\alpha$ coefficients. Given the robustness of the dimensional structure that emerged from this exploratory analysis, the extracted factors were interpreted before running a confirmatory test. Consistent with Study 1's findings, the first factor ( $\alpha=0.86)$ was mainly loaded by items that capture re-gifters' aim to maximize their personal utility (e.g., "If I needed to save money I would pass on one of my gifts") and was therefore named Individualistic motivation. The second factor $(\alpha=0.81)$ was mainly loaded by items that 
capture re-gifters' willingness to maintain or increase their distance from a potentially disliked re-giftee (e.g., "I would pass on a gift to give it to a person I dislike") or first giver ("I would pass on a gift received from a person whom I dislike"). It was therefore named Detachment motivation. The third factor $(\alpha=0.70)$ was mainly loaded by items that capture the re-gifters' willingness to pass on their gifts to benefit others (e.g., "I would pass on one of my gifts if I were sure that it would be appreciated") and, in more general terms, act in a morally acceptable way by putting unwanted gifts to use (e.g., "If I had two identical gifts, I would pass on one of them"). Thus, it was named Virtuous motivation.

A confirmatory factor analysis provided definitive support for the dimensional structure that emerged in the exploratory test. The results summarized in Table 4 support the validity of the tridimensional model. Fit statistics were acceptable. The factor loadings were adequate except for one item within the Virtuous motivation ("If I received a highly valuable gift, I would give it to someone that is very important to me"), which, as mentioned above, was retained in the scale. We checked the construct reliability for each of the three motivations following Fornell and Larcker's (1981) suggestions. The adequate results (construct reliability indexes $>0.60$; Hair et al., 1998) provide evidence of convergent validity. We then checked discriminant validity by following the procedure recommended by Anderson and Gerbing (1988). This entailed constraining the tridimensional model against a series of alternative models with pairwise restrictions on inter-factor covariances, which were fixed at 1.0. The $\chi^{2}$ difference tests confirmed that the original model with three distinct latent factors performed better than the alternative models with pairwise restrictions. Hence, these results affirm the validity of the proposed tridimensional scale as a measurement tool to quantitatively assess the main re-gifting motivations.

Table 4 about here 


\section{Study 3: Validation of the tridimensional nature of re-gifting motivations}

Study 3 examines the predictive validity of the scale by assessing how each of the three regifting motivations identified in Studies 1 and 2 varies in intensity depending on whether the re-giftee is a close or a distant other.

The results of Studies 1 and 2 suggest that the individualistic and detachment motivations represent egoistic drivers that might lead re-gifters to pursue self-interest when re-gifting, whereas the virtuous motivation expresses re-gifters' altruistic intent to care for re-giftees and, in general, act in a morally desirable way. Concurrently, previous literature (Small \& Simonsohn, 2008; Ward \& Broniarczyk, 2011) suggests that people normally adopt a more egoistic perspective when interacting with distant others, thus prioritizing their self-interest, and a more altruistic perspective when interacting with close others, thus prioritizing greater generosity. Based on this reasoning, we tested whether the three re-gifting motivations vary as a function of the re-giftees' distance or closeness. In particular, we expected that the individualistic and detachment motivations would be stronger when re-giftees are distant rather than close others, whereas the virtuous motivation would be stronger when re-giftees are close rather than distant others.

\subsection{Procedure}

A different sample of 400 people, drawn from another pool of Italian consumers, received an invitation to participate in an online survey on re-gifting. The invitation featured a link to the survey and specified that the survey was intended only for people who had passed on a gift to someone else at least once in their life. Those who accessed the electronic questionnaire were asked to briefly describe a real occasion in which they passed on their gift, who the first giver was, and what item they re-gifted. Then, respondents were asked to rate how expensive that gift was compared to how much they usually spend for gifts using a 
seven-point scale $(1=$ Not expensive at all, $7=$ Very expensive $)$ and how relevant that gift was to themselves $(1=$ Not relevant at all, $7=$ Very relevant $)$. Next, they were asked to think of the person to whom they passed on the gift and rate their relationship with that person along four items, which were drawn from Sedikides, Campbell, Reeder, and Elliott (1999) and assessed on seven-point scales. Specifically, those four items asked respondents to indicate how close they felt to that person $(1=$ Not close at all, $7=$ Very close $)$, how similar they felt to that person $(1=$ Not similar at all, $7=$ Very similar $)$, how much they liked that person $(1=$ Not at all, $7=$ Very much $)$, and how likely they would be to maintain the relationship with that person in the future $(1=$ Not likely at all, $7=$ Very likely $)$. Respondents then indicated the motivations that led them to pass on their gifts in the recalled occasion by completing the scale as developed in Study 2 (e.g., "I passed on my gift because..." "...doing so allowed me to save money", “...I was sure that that gift would have been appreciated”, “...I did not feel linked to the person to whom I gave that gift"; $1=$ Strongly disagree, $7=$ Strongly agree). Finally, respondents indicated their gender, age, and annual income.

\subsection{Results}

One hundred and seventy individuals (mean age $=35, S D=12.18,50 \%$ females) completed the full questionnaire. A frequency analysis of the recalled re-gifting occasions revealed that the most frequent re-gifting occasions were Christmas $(48 \%$ of all recalled occasions) and birthdays (30\%). In the majority of cases (55\%), respondents received the gift they passed on from a person they generically defined as "friend", whereas the objects regifted were most often clothes (12\%) and gift cards (7\%).

The data were analyzed using a mixed ANOVA, with type of re-gifting motivation set as a within-subjects factor on three levels (i.e., individualistic, detachment, and virtuous re-gifting motivation) and relational closeness set as a continuous covariate. Relational closeness was 
computed by averaging the scores of the four items regarding perceived closeness, similarity, liking for the re-giftee, and likelihood of maintaining the relationship with that person $(\alpha=$ .89). The analysis returned a significant main effect for both the type of re-gifting motivation $\left(F(2,336)=28.21, p<.001, \eta^{2}=.11\right)$ and relational closeness $(F(1,168)=23.76, p<.001$, $\eta^{2}=.12$ ). More importantly, these effects were qualified by a significant interaction between type of re-gifting motivation and relational closeness $\left(F(2,336)=52.35, p<.001, \eta^{2}=.21\right)$. This interaction effect remained significant $(p<.001)$ even after controlling for the other two product-related covariates (i.e., the gift's expensiveness and relevance) and the three sociodemographic characteristics (i.e., age, gender, and annual income).

To probe the nature of this interaction, we computed the correlation between relational closeness and each type of motivation, finding that relational closeness is negatively correlated with both individualistic $(r=-.44, p<.001)$ and detachment motivations $(r=-.47$, $p<.001)$, and positively correlated with the virtuous motivation $(r=.30, p<.001)$. For illustrative reasons, we repeated the analysis using a dichotomized version of the relational closeness variable. This dichotomous variable was computed based on median-split $(M d n=$ 5.00), which defined two groups of respondents depending on whether their relational closeness score was lower or higher than the median value: one group re-gifted a relatively distant other, whereas the other group re-gifted a closer other. Contrasts revealed that the individualistic re-gifting motivation was stronger for respondents who re-gifted a distant other $(M=4.17, S D=1.25)$ than a closer one $(M=3.12, S D=1.29), F(1,168)=29.31, p<.001, \eta^{2}$ $=.15$. Similarly, the detachment motivation was stronger for respondents who re-gifted a distant other $(M=2.67, S D=1.42)$ than a closer one $(M=1.56, S D=1.10), F(1,168)=$ $32.60, p<.001, \eta^{2}=.16$. Conversely, the virtuous re-gifting motivation was weaker for respondents who re-gifted a distant other $(M=3.65, S D=.94)$ than a closer one $(M=4.27$, $S D=1.04), F(1,168)=16.33, p<.001, \eta^{2}=.09$. Such results confirm that the re-gifting 
motivations vary in intensity depending on the relational closeness between re-gifters and regiftees.

\section{Discussion and conclusions}

Despite the growing acceptance of re-gifting (e.g., American Express, 2013), current research still lacks a parsimonious interpretative model of re-gifting motivations and a measurement scale that assesses such motivations. To address this gap, the present work adopted a mixed approach that combines qualitative and quantitative research techniques to develop a measurement scale of re-gifting motivations. The obtained results support a tridimensional conceptualization of such motivations and suggest that individuals might engage in re-gifting to maximize their personal utility (individualistic motivation), distance themselves from other persons (detachment motivation), or act in a morally desirable way by pleasing others and/or putting unwanted gifts to use (virtuous motivation).

The proposed tridimensional model of consumers' re-gifting motivations appears more inclusive than other relevant models proposed in previous seminal studies (Ertimur et al., 2015). Capturing the pragmatic side of re-gifting, the individualistic motivation denotes regifters' primary focus on their self-interest and hence their view of re-gifting as a type of selfish behavior. Consistent with Ertimur et al.'s (2015) study, the detachment motivation captures re-gifters' willingness to signal their relational distance from re-giftees (or first givers), which, in particular cases, might arise from a desire to retaliate against previous unfriendly or hostile actions by re-giftees. Finally, the virtuous motivation not only encompasses the altruistic mode of re-gifting, in that it reflects re-gifters' willingness to benefit re-giftees, but also reflects re-gifters' consciousness about the economic and environmental sustainability of their decisions to pass along second-hand gifts. This latter 
motivation, which did not clearly emerge from prior research, further evidences that re-gifting cannot always be considered as a merely deceitful behavior.

We did not identify the playful re-gifting motivation that was found in U.S.-based studies (Ertimur et al., 2015; see also Swilley et al., 2014). Our use of an Italian context might have affected this outcome, which suggests that cultural factors may impact re-gifting motivations, even across modern Western societies (Ertimur et al., 2014). Furthermore, we empirically show that the relative strength of re-gifting motivations significantly changes depending on the relational closeness between re-gifters and re-giftees. Specifically, close relations more strongly activate the virtuous motivation, while distant relations more strongly activate the individualistic and detachment motivations.

This research features some limitations that present fruitful areas for future investigations. The scale used here to assess re-gifting motivations was developed by surveying a sample of relatively young consumers living in Italy, a country where re-gifting is commonly accepted (Coldiretti, 2015). Future research could try to generalize the validity of this scale by applying it to samples from other countries where re-gifting might be more or less socially acceptable (Swilley et al., 2014; also Beatty, Kahle, \& Homer, 1991). Likewise, future studies could also examine possible relationships between re-gifting motivations and cultural factors (e.g., individualism versus collectivism; Hofstede, Hofstede, \& Minkov 2010; Park, 1988). Finally, researchers could also investigate how re-gifting motivations might vary across particular market segments. Frugal consumers (Ballantine \& Creery, 2010), for instance, might be mainly driven by the virtuous motivation, whereas older consumers (Author, 2014; Moschis, 2003), limited by factors such as personal mobility or inertia, might be more driven by the individualistic motivation. Such investigations might further increase our understanding of the significance of this under-researched behavior. 


\section{References}

Adams, G. S., Flynn, F. J., \& Norton, M. (2012). The gift we keep on giving: Documenting and destigmatizing the re-gifting taboo. Psychological Science, 23(10), 1145-1150.

Adweek (2012). Gyft takes the taboo out of regifting, through Facebook, http://www.adweek.com/socialtimes/gyft/407709. Accessed 19-3-2016.

American Broadcasting Company, ABC News (2014). Expert tips for re-gifting your unwanted holiday gifts, http://abcnews.go.com/Lifestyle/expert-tips-gifting-unwantedholiday-gifts/story?id=27836613. Accessed 9-3-2016.

American Express (2013). Spending \& saving tracker, http://www.google.it/url?sa=t\&rct=j\&q=\&esrc=s\&source=web\&cd=3\&cad=rja\&uact $=8 \&$ ved $=0 \mathrm{CD} 8 \mathrm{QFjAC \& url=http} \% 3 \mathrm{~A} \% 2 \mathrm{~F} \% 2 \mathrm{Fabout}$. americanexpress.com $\% 2 \mathrm{Fnews} \% 2 \mathrm{Fsst} \%$ 2Freport\%2F2013-12_Spend-and-SaveTracker.pdf\&ei=COsnVam8MJDPaK3qgpgC\&usg=AFQjCNHp6S7LW9Qp_qryraEeZ mSjC3Gwg\&bvm=bv.90491159,d.ZWU. Accessed 10-3-2015.

Anderson, J. C., \& Gerbing, D. W. (1988). Structural equation modeling in practice: A review and recommended two-step approach. Psychological Bulletin, 103(3), 411-423.

Ballantine, P., \& Creery, S. (2010). The consumption and disposition behavior of voluntary simplifiers. Journal of Consumer Behavior, 9(1), 45-56.

Beatty, S. E., Kahle, L. R., \& Homer, P. (1991). Personal values and gift-giving behaviors: A study across cultures. Journal of Business Research, 22(2), 149-157.

Belk, R. W. (1979). Gift giving behavior. Research in Marketing, 2, 95-126.

Belk, R. W., \& Coon, G. S. (1993). Gift giving as agapic love: An alternative to the exchange paradigm based on dating experiences. Journal of Consumer Research, 20(3), 393-417.

Blankson, C. (2008). Measuring college students' choice criteria of credit cards: Scale development and validation. Journal of Marketing Management, 24(3-4), 317-344. 
Caplow, T. (1982). Christmas gifts and kin networks. American Sociological Review, 47(3), 383-392.

Caplow, T. (1984). Rule enforcement without visible means: Christmas gift giving in middletown. American Journal of Sociology, 89(6), 1306-1323.

Carrigan, M., \& Attalla, A. (2001). The myth of the ethical consumer-Do ethics matter in purchase behaviour? Journal of Consumer Marketing, 18(7), 560-578.

Carson, D., Gilmore, A., Perry, C., \& Gronhaug, K. (2001). Qualitative marketing research, London: Sage.

Cheal, D. (1988). The gift economy. New York: Routledge.

Churchill, G. A. Jr. (1979). The role of involvement in attention and comprehension processes, Journal of Consumer Research, 15(2), 210-224.

Coldiretti (2014). Natale: Coldiretti, 1 Italiano su 3 ricicla i Regali (+2\%), http://www.coldiretti.it/News/Pagine/858--\%E2\%80\%93-28-Dicembre-2014.aspx. Accessed 11-8-2015.

Coldiretti (2015). Natale: Coldiretti, per 1 italiano su 5 riciclo regali al via. http://www.coldiretti.it/News/Pagine/930-\%E2\%80\%93-28-Dicembre-2015.aspx Accessed 16-3-2016.

Columbia Broadcasting System, CBS (2015). Rules for regifting this holiday season, http://philadelphia.cbslocal.com/2015/12/26/rules-for-re-gifting-this-holiday-season. Accessed 9-3-2016.

Cruz-Cárdenas, J., González, R., \& del Val Núñez, M. T. (2015). The use of disliked gifts from a consumer behavior perspective. Journal of Business Research, 68(7), 1635-1637. Curasi, C. F., Price, L. L., \& Arnould, E. J. (2004). How individuals' cherished possessions become families' inalienable wealth. Journal of Consumer Research, 31(3), 609-622. 
Ertimur, B., Muñoz, C., \& Hutton, J. (2015). Regifting: A multi-perspective processual overview. Journal of Business Research, 68(9), 1997-2004.

Fornell, C., \& Larcker, D. F. (1981). Evaluating structural equations models with unobservable variables and measurement error. Journal of Marketing Research, 18(1), 3950.

Gallup (2013). Americans' projected holiday spending up slightly from 2013, available at: http://www.gallup.com/poll/179552/americans-projected-holiday-spending-slightly2013.aspx. Accessed 21-6-2015.

Gerbing, D. W., \& Anderson, J. C. (1988). An updated paradigm for scale development incorporating unidimensionality and its assessment. Journal of Marketing Research, 25 (2), 186-192.

Gouldner, A. W. (1960). The norm of reciprocity: A preliminary statement. American Sociological Review, 25(2), 161-178.

Green America (2016). Our favorite green gifts and traditions. Ideas from Green America staff and members. http://www.greenamerica.org/pubs/greenamerican/articles/NovDec2012/green-gifts-andtraditions-from-green-america-staff-and-members.cfm. Accessed 20-2-2016.

Joy, A. (2001). Gift giving in Hong Kong and the continuum of social ties. Journal of Consumer Research, 28(2), 239-256.

Hair, J. F., Anderson, R. E., Tatham, R. L., \& Black, W. C. (1998). Multivariate analysis. Upper Saddle River: Prentice-Hall.

Hofstede, G., Hofstede, G. J., \& Minkov, M. (2010). Cultures and organizations: Software of the mind. New York: McGraw-Hill.

Kassarjian, H. H. (1977). Content analysis in consumer research. Journal of Consumer Research, 4(1), 8-18. 
Lowrey, T. M., Otnes, C. C., \& Ruth, J. A. (2004). Social influences on dyadic giving over time: A taxonomy from the giver's perspective. Journal of Consumer Research, 30(4), $547-558$.

Malcarne, V. L., Chavira, D. A., Fernandez, S., \& Liu, P. J. (2006). The scale of ethnic experience: Development and psychometric properties. Journal of Personality Assessment, $86(2), 150-161$.

Malinowski, B. (1978). Argonatus of the Western Pacific: An account of native enterprise and adventure in the archipelagoes of Melanesian New Guinea. New York: Routledge.

Mansvelt, J., \& Robbins, P. (2011). Green consumerism. An A-to-Z guide. Thousand Oaks: Sage.

Marcoux, J.-S. (2009). Escaping the gift economy. Journal of Consumer Research, 36(4), $671-685$

Mauss, M. (1925). The gift: Forms and functions of exchange in archaic societies. New York: Norton.

Moschis, G. P. (2003). Marketing to older adults: An updated overview of present knowledge and practice. Journal of Consumer Marketing, 20(6), 516-525.

Ormandy, E. M. (2011). Examining the behavior of re-gifting using a multi-method approach. (Unpublished Thesis, University of Canterbury).

Otnes, C. C., \& Beltramini, R. F. (1996). Gift giving: A research anthology. Bowling Green: Bowling Green State University Popular Press.

Otnes, C. C., Lowrey, T. M., \& Kim, Y. C. (1993). Gift selection for easy and difficult recipients: A social roles interpretation. Journal of Consumer Research, 20(2), 229-244.

Paolacci, G., Straeter, L. M., \& de Hooge, I. (2015). Give me your self: Gifts are liked more when they match the giver's characteristics. Journal of Consumer Psychology, 25(3), 487494. 
Park, S. Y. (1998). A comparison of Korean and American gift-giving behaviors. Psychology \& Marketing, 15(6), 577-593.

Russell, C. A., Norman A. T., \& Heckler, S. E. (2004). The consumption of television programming: Development and validation of the connectedness scale. Journal of Consumer Research, 31(1), 150-161.

Ruth, J. A., Otnes, C. C., \& Brunel, F. F. (1999). Gift receipt and the reformulation of interpersonal relationships. Journal of Consumer Research, 25(4), 385-402.

Saad, G., \& Gill, T. (2003). An evolutionary psychology perspective on gift giving among young adults. Psychology \& Marketing, 20(9), 765-784.

Sedikides, C., Capbell, W. K., Reeder, G. D., \& Elliott, A. J. (1999). The relationship closeness induction task. Representative Research in Social Psychology, 23, 1-4.

Segev, R., Shoham, A., \& Ruvio, A. (2012). What does this gift say about me, you, and us? The role of adolescents' gift giving in managing their impressions among their peers. Psychology \& Marketing, 29(10), 752-764.

Schwartz, B. (1967). The social psychology of the gift. American Journal of Sociology, 73(1), $1-11$

Sherry, J. F. (1983). Gift giving in anthropological perspective. Journal of Consumer Research, 10(2), 157-168.

Small, D. A., \& Simonsohn, U. (2008). Friends of victims: Personal experience and prosocial behavior. Journal of Consumer Research, 35(3), 532-542.

Spiggle, S. (1994). Analysis and interpretation of qualitative data in consumer research. Journal of Consumer Research, 21(3), 491-503.

Stewart, D. W., Shamdasani, P. N., \& Rook, D. (2006). Focus group: Theory and practice, London: Sage. 
Swilley, E., Cowart, K. O., \& Flynn, L. R. (2014). An examination of re-gifting. Journal of Consumer Behavior, 13(4), 251-261.

Van Dun, Z., Bloemer, J., \& Henseler, J. (2011). Perceived customer contact centre quality: conceptual foundation and scale development. The Service Industries Journal, 31(8), 13471363.

Waldfogel, J. (1993). The deadweight loss of Christmas. American Economic Review, 83(5), $1328-1336$.

Ward, M. K., \& Broniarczyk, S. M. (2011). It's not me, it's you: How gift giving creates giver identity threat as a function of social closeness. Journal of Consumer Research, 38(1), 164181.

Waterman, A. S. (1981). Individualism and interdependence. American Psychologist, 36(7), $762-773$. 


\section{Figures}

\section{Figure 1}

Re-gifting motivations as a function of the relational distance between re-gifters and regiftees.

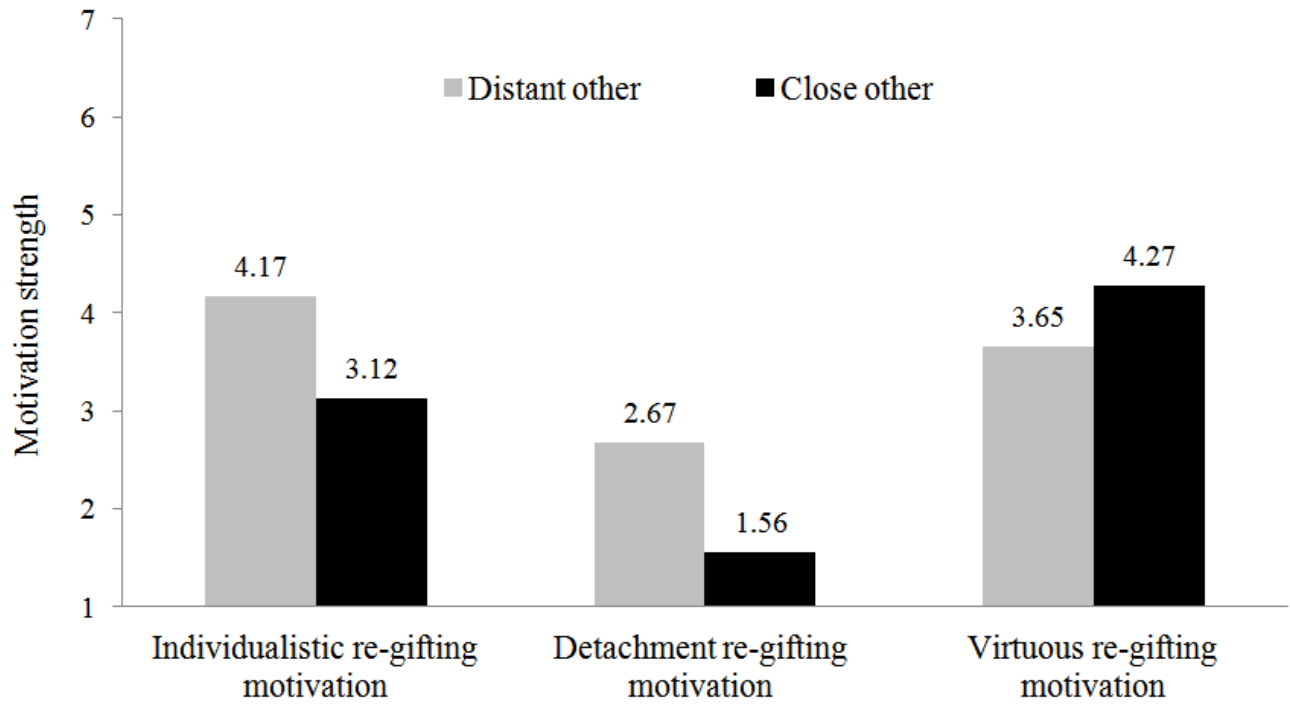




\section{Tables}

\section{Table 1}

Focus group participants' demographic data.

\begin{tabular}{|c|c|c|c|c|c|c|c|}
\hline \multicolumn{4}{|c|}{ Focus group 1} & \multicolumn{4}{|c|}{ Focus group 2} \\
\hline Participant & Job & Gender & Age & Participant & Job & Gender & Age \\
\hline 1 & Chiropatic & Male & 25 & 17 & Student & Male & 26 \\
\hline 2 & Technician & Male & 26 & 18 & Photographer & Male & 32 \\
\hline 3 & Counselor & Female & 32 & 19 & Architect & Male & 41 \\
\hline 4 & Engineer & Male & 38 & 20 & Clerk & Male & 29 \\
\hline 5 & Physician & Female & 45 & 21 & Lecturer & Male & 35 \\
\hline 6 & Technician & Male & 27 & 22 & Biologist & Female & 40 \\
\hline 7 & Policeman & Male & 27 & 23 & Lawyer & Female & 35 \\
\hline 8 & Surgeon & Male & 42 & 24 & Home-maker & Female & 31 \\
\hline 9 & Area manager & Female & 36 & 25 & Shop assistant & Female & 26 \\
\hline 10 & Sales manager & Female & 34 & 26 & Nurse & Female & 29 \\
\hline 11 & Optician & Female & 30 & 27 & Teacher & Female & 44 \\
\hline 12 & Undergraduate & Female & 25 & 28 & Executive & Male & 49 \\
\hline 13 & Executive & Male & 43 & 29 & Interpreter & Male & 30 \\
\hline 14 & Nurse & Female & 41 & 30 & Librarian & Female & 50 \\
\hline 15 & Teacher & Female & 28 & 31 & Physioterapist & Male & 26 \\
\hline 16 & Student & Male & 26 & 32 & Caregiver & Female & 32 \\
\hline
\end{tabular}

Table 2

Re-gifting motivations.

\begin{tabular}{|c|c|c|}
\hline $\begin{array}{l}\text { Individualistic } \\
\text { motivations }\end{array}$ & $\begin{array}{l}\text { Detachment } \\
\text { motivations }\end{array}$ & $\begin{array}{l}\text { Virtuous } \\
\text { motivations }\end{array}$ \\
\hline $\begin{array}{l}\text { - Scarcity of economic resources } \\
\text { - Scarcity of time } \\
\text { - Possibility to avoid the efforts } \\
\text { needed to buy a new gift } \\
\text { - Availability of wrapped gifts } \\
\text { - Indecision in the choice of a } \\
\text { gift } \\
\text { - Entitlement of freely disposing } \\
\text { of one's own gifts } \\
\text { - Lack of concern about the } \\
\text { consequence of re-gifting }\end{array}$ & $\begin{array}{l}\text { - Reciprocation of re- } \\
\text { gifting } \\
\text { - Loose relationship with } \\
\text { the re-giftee } \\
\text { - Loose relationship with } \\
\text { the first giver } \\
\text { - Desire to rid oneself of } \\
\text { gifts that have lost their } \\
\text { affective meaning } \\
\text { - Opportunity to } \\
\text { accomplish a sense of } \\
\text { social obligation }\end{array}$ & $\begin{array}{l}\text { - Availability of gifts likely } \\
\text { to be appreciated by the } \\
\text { re-giftee } \\
\text { - Availability of highly } \\
\text { valuable gifts } \\
\text { - Availability of duplicate } \\
\text { gifts } \\
\text { - Possibility to preserve the } \\
\text { economic value of a } \\
\text { disliked gift }\end{array}$ \\
\hline
\end{tabular}


Table 3

Likelihood to engage in re-gifting across the possible categories of re-giftees.

\begin{tabular}{lccc}
\hline Categories of re-giftees & M & SD & Loadings \\
\hline Close others: & & & \\
$\quad$ Siblings & 2.20 & 1.98 & $0.94^{*}$ \\
Parents & 2.13 & 1.96 & $0.93^{*}$ \\
Grandparents & 2.18 & 1.95 & $0.87^{*}$ \\
Partner & 1.99 & 1.95 & $0.86^{*}$ \\
Close friends & 2.15 & 1.91 & $0.85^{*}$ \\
Distant others: & & & \\
Acquaintances & 3.85 & 2.11 & $0.95^{*}$ \\
Colleagues & 3.56 & 2.07 & $0.94^{*}$ \\
Employers & 3.40 & 2.09 & $0.83^{*}$ \\
\hline
\end{tabular}

$\mathrm{N}=171 ; *=$ level of significance equal to 0.001 .

\section{Table 4}

Results of the confirmatory factor analysis: a scale to measure the re-gifting motivations.

\begin{tabular}{|c|c|c|}
\hline Latent factors and indicators & FL & SE \\
\hline \multicolumn{3}{|l|}{ Individualistic motivation $(C R=0.81 ; A V E=0.44)$ : } \\
\hline If I needed to save time, I would pass on my gifts. & $0.82^{\text {n.a. }}$ & - \\
\hline I would pass on one of my gifts because I am free to do whatever I want with them. & $0.67^{*}$ & 0.11 \\
\hline If I did not know what to give to someone, I would pass on one of my gifts. & $0.69 *$ & 0.09 \\
\hline If I needed to save money, I would pass on one of my gifts. & $0.77 *$ & 0.10 \\
\hline I would pass on a gift because I do not care about what the recipient will do with it. & $0.53 *$ & 0.10 \\
\hline I would pass on one of my gifts If I felt too tired to buy a new one. & $0.40 *$ & 0.07 \\
\hline \multicolumn{3}{|l|}{ Detachment motivation of re-gifting $(C R=0.79 ; A V E=0.56)$ : } \\
\hline I would pass on one of my gifts to a person I dislike. & $0.83^{\text {n.a }}$ & - \\
\hline I would pass on a gift received from a person I dislike. & $0.71 *$ & 0.10 \\
\hline I would pass on one of my gifts to a person to whom I am not particularly tied. & $0.69 *$ & 0.10 \\
\hline \multicolumn{3}{|l|}{ Virtuous motivation $(C R=0.65 ; A V E=0.34)$ : } \\
\hline If I had two identical gifts, I would pass on one of them. & $0.69^{\text {n.a }}$ & - \\
\hline I would pass on one of my gifts rather than throw it away. & $0.67 *$ & 0.15 \\
\hline I would pass on one of my gifts if I were sure that it would be appreciated. & $0.60 *$ & 0.15 \\
\hline $\begin{array}{l}\text { If I received a highly valuable gift, I would give it to someone that is very } \\
\text { important to me. }\end{array}$ & $0.30^{*}$ & 0.12 \\
\hline
\end{tabular}

$\mathrm{N}=171 ;$ n.a. $=$ Not applicable; $*=$ level of significance equal to $0.001 ; \mathrm{FL}=$ Factor Loadings; $\mathrm{SE}=\mathrm{Standard}$ Error; $\chi^{2}(64)=107.773, \mathrm{p}<0.001 ; \chi^{2} /$ g.d.1. $=1.684 ; \mathrm{GFI}=0.913 ; \mathrm{AGFI}=0.876 ; \mathrm{CFI}=0.952 ; \mathrm{RMSEA}=0.063$ $(p=0.15) ; \mathrm{SRMR}=0.054 ; \mathrm{CR}=$ Construct Reliability; AVE $=$ Average Variance Extracted. 